\title{
Considerations for effective science communication
}

\begin{abstract}
Steven J. Cooke ${ }^{\mathrm{a} \star}$, Austin J. Gallagher ${ }^{\mathrm{bc}}$, Natalie M. Sopinka ${ }^{\mathrm{d}}$, Vivian M. Nguyen ${ }^{\mathrm{a}}$, Rachel A. Skubel ${ }^{\mathrm{ce}}$, Neil Hammerschlag ce, Sarah Boon ${ }^{\text {f }}$, Nathan Young, and Andy J. Danylchuk ${ }^{\mathrm{h}}$

${ }^{a}$ Fish Ecology and Conservation Physiology Laboratory, Department of Biology and Institute for Environmental Science, Carleton University, Ottawa, ON K1S 5B6, Canada; ${ }^{\mathrm{b}}$ Beneath the Waves, Inc., Miami, FL 33149, USA; ${ }^{c}$ Rosenstiel School of Marine and Atmospheric Science, University of Miami, Miami, FL 33149, USA; 'Great Lakes Institute for Environmental Research, University of Windsor, Windsor, ON N9C 1A2, Canada; ${ }^{\mathrm{e}}$ Abess Center for Ecosystem Science \& Policy, University of Miami, Miami, FL 33146, USA; ${ }^{\mathrm{f}}$ Creekside Communication, Cobble Hill, BC V0R 1L6, Canada; ${ }^{\mathrm{g}}$ Department of Sociology and Anthropology, University of Ottawa, Ottawa, ON K1N 6N5, Canada; ${ }^{\mathrm{h}}$ Department of Environmental Conservation, University of Massachusetts, Amherst, MA 01003, USA
\end{abstract}

*Steven.Cooke@carleton.ca

\section{Abstract}

It is increasingly common for scientists to engage in sharing science-related knowledge with diverse knowledge users - an activity called science communication. Given that many scientists now seek information on how to communicate effectively, we have generated a list of 16 important considerations for those interested in science communication: (1) Define what science communication means to you and your research; (2) Know-and listen to-your target audience; (3) Consider a diverse but coordinated communication portfolio; (4) Draft skilled players and build a network; (5) Create and seize opportunities; (6) Be creative when you communicate; (7) Focus on the science in science communication; (8) Be an honest broker; (9) Understand the science of science communication; (10) Think like an entrepreneur; (11) Don't let your colleagues stop you; (12) Integrate science communication into your research program; (13) Recognize how science communication enhances your science; (14) Request science communication funds from grants; (15) Strive for bidirectional communication; and (16) Evaluate, reflect, and be prepared to adapt. It is our ambition that the ideas shared here will encourage readers to engage in science communication and increase the effectiveness of those already active in science communication, stimulating them to share their experiences with others.

Key words: science engagement, science outreach, communication science, evaluation of science communication, academic cultures, professional development

\section{Context}

In the broadest sense, effective science communication is the sharing of science-related knowledge whereby one's efforts have a palpable impact on knowledge users (Burns et al. 2003). Much like teaching, there is no single approach to science communication (Weigold 2001), and thus no single recipe for success. The audiences of non-experts with whom scientists interact are highly diverse: from interested to non-interested laypeople, engaged stakeholders and policymakers, and scientific colleagues from other disciplines. The reasons scientists give for engaging in science communication are also quite varied (Poliakoff and Webb 2007), including: grant requirements, a genuine interest in public engagement, and feelings of moral obligation. The intended outcomes of science 
communication activities also range from changing human behaviour (e.g., increasing participation in recycling programs, influencing how someone might vote) to simply educating, informing, or entertaining an audience.

For the last half century, science communication has primarily been the responsibility of teachers, outreach coordinators, or trained science writers and journalists with a penchant for translating often complicated science into compelling storylines or concepts easily understood by non-expert publics (Durant et al. 1989). Today, scientists themselves often engage in some form(s) of science communication beyond peer-reviewed publications, which primarily target their peers. This occurs irrespective of sector (e.g., government, academic, or industry) or career stage (i.e., graduate student, senior scientist, or emeritus professor). Although many scientists do science communication voluntarily, it is also increasingly expected of scientists (explicitly or implicitly) and can even be a specific institutional requirement for some researchers (e.g., through tenure and promotion evaluations and (or) granting/ funding bodies). We presume that some scientists want to do science communication, whereas others feel obligated to do it.

Given that most scientists lack formal training in science communication, it is not surprising to observe a variety of efforts and outcomes (Treise and Weigold 2002). For that reason, many members of the scientific community actively seek input, ideas, and inspiration on science communication from specialists (e.g., a public relations or communications office at their institution), non-scientific institutions (e.g., businesses), and colleagues who are known for successful communication experiences or initiatives. Indeed, science communication is now featured at academic conferences, embedded in professional development workshops at academic institutions, discussed in prominent news outlets, critiqued by political pundits, and mused about in the digital realm. Science communication has even served as an intermediate form of peer review (e.g., the \#arseniclife story; Yeo et al. In press). There are now scholarly papers, several of which draw on the rich literatures of education and communication theory (e.g., Logan 2001; Glanz and Bishop 2010). These include topics such as how to engage in the delivery of various elements of science communication (e.g., how to use social media effectively (Parsons et al. 2013), and how to deliver an effective TED-style talk (Sugimoto et al. 2013)).

The typical scientist is thus more active and engaged in science communication than they were a decade ago (Liang et al. 2014). Given that many scientists seek information on how to communicateor how to communicate better-we have generated a list of key considerations and tips for those interested in engaging in science communication. This list is not intended to be prescriptive, nor do we assume that all considerations are relevant to all readers. This list is also not a how-to guide, although we do provide a list of key references related to science communication, which can be further pursued by readers (Table 1 ).

We submit that science communication can be tailored to fit the motives, time commitments, resources, and personality of a given scientist or research group, and the specific topic, study species, system, or process that they wish to share. We provide some ideas on possible ways to do so. We recognize that this list is not exhaustive and that there are many benefits that accrue to the individual science communicator, to the scientific enterprise more broadly, as well as to society as a whole (see Nisbet and Scheufele 2009). Our perspective is shaped by the fact that all of the authors here are engaged in environmental science and, as such, most of the examples that we present have links to the environment. Nonetheless, we submit that the tips that we list here are broadly relevant to scientists in any discipline interested in science communication. The text is minimally referenced in an effort to maintain focus on the elegant simplicity of the tips. Although we focus on efforts where simple and specific actions can be undertaken by the would-be science communicator, this is not intended to detract from the important two-way nature of some communication strategies and approaches that science communicators should strive for. 
Table 1. Key resources on science communication for scientists.

American Academy for the Advancement of Science

Small Pond Science List of Science Communication Resources

Iowa State University Science Communication Project

Canadian Science Publishing-Science Communication and Media

Union of Concerned Scientists-Tips and Tools for Science Communicators

Integration and Application Network

Inspiring Australia-Science Communication Toolkit

European Commission-Guide to Successful

Communication aaas.org/pes/communicating-science-resources

smallpondscience.com/2015/10/08/useful-science-communication-resources/

scicomm.las.iastate.edu/our-work/science-communication-resources-around-the-web/

cdnsciencepub.com/learning-centre/communications-and-media/

ucsusa.org/action/science_network/tips-and-tools.html\#.WCnhePorI2w

ian.umces.edu/learn/science_communication/

inspiringaustralia.net.au/toolkit/

ec.europa.eu/research/science-society/science-communication/index_en.htm and

livingknowledge.org/fileadmin/Dateien-Living-Knowledge/Dokumente_Dateien/Toolbox/

LK_C_Communicating_Science_Kit.pdf

See their blog and COMPASS Points compassonline.org

\section{Considerations}

\section{Define what science communication means to you and your research}

Conceptualizing why we, as scientists, do our work may be a helpful exercise in determining whether or not to proceed with science communication. If the answer is to increase the spread of knowledge and (or) be a driving force in changing policy or decision-making, then science communication is clearly relevant to accomplishing those goals. Subsequent questions can be used to define exactly what types of communication efforts are best suited to our research programs.

Although some scientists limit themselves to sharing ideas via social media, others are more interested in in-person science communication activities such as public events. Ultimately, you must decide what audience you want to reach, what your objectives are for communicating science (a step that also helps when measuring success later on), and determine the best approach to engage that audience given your available time, abilities, and resources. The more comfortable you are with your chosen communication technique, the more effective it will be.

\section{Know-and listen to-your target audience}

Every audience is different, not only demographically but also with respect to background knowledge, personality, worldview, cultural norms, and preferences. Indeed, in some cases, science communication efforts focusing on non-interested or hostile demographics may be part of a broader plan to increase education around politically controversial topics (i.e., climate change, vaccination). Knowing your audience is critical for connecting with them (Wilson et al. 2016). Getting to know your audience also takes forethought, observation, imagination, and, yes, research. Think critically about what aspect of your science is best suited to the target audience. It is also important that the information you share is of appropriate complexity. For example, you would describe your research process differently to a group of undergraduates than to policymakers-and even specialized audiences like policymakers are not homogeneous. Get to know the people with whom you are attempting to communicate. 


\section{Consider a diverse but coordinated communication portfolio}

In today's media landscape, a strikingly wide range of communication strategies, platforms, avenues, channels, and techniques are available even to less technologically savvy scientists. A scattershot approach, however, is less effective than a planned and coordinated one. Reaching multiple target audiences in ways that they find convenient and credible requires strategy. For example, peer-reviewed articles are seen as highly credible sources to scientists, but others find them difficult to access and interpret. If you coordinate the publication of a new research paper with an accompanying infographic, blog post, video summary, Twitter campaign, or press release, news of your research can reach a much larger audience while maintaining the credibility of peer review.

\section{Draft skilled players and build a network}

Venturing into the uncharted waters of science communication can be an intimidating experience, particularly for researchers with little experience. Once you've decided on a particular approach or message, consider creating a collaborative team that integrates both newcomers and veterans of the trade. In some cases, for example, graduate students and junior scholars have become science communication leaders in their research communities, and subsequently mentor their more senior colleagues. In addition, many institutions have a dedicated fundraising/ advancement or public relations team, which includes communication and outreach staff. Seek out this team to help you develop and implement science communication programs. Another group that is receiving attention in science communication research is knowledge brokers (e.g., Meyer 2010). Knowledge brokers are people who (intentionally or unintentionally) connect different groups such as academia and industry or government, and therefore serve as key conduits for the movement of knowledge and influence. Although it is sometimes difficult to identify knowledge brokers, they are potentially highly valuable members of your network.

\section{Create and seize opportunities}

Seeking out opportunities for science communication is crucial. Journalists, for example, sometimes contact researchers to cover their work, whereas researchers sometimes pitch ideas directly to journalists. Being able to create these opportunities and also to seize serendipitous opportunities is critical for amplifying your message. Another aspect of seizing opportunity includes finding ways to improve your own science communication skills via programs like the Aldo Leopold Fellowship Program, conference workshops, or media training through an academic institution.

\section{Be creative when you communicate}

Creativity entails generating new ideas and this is an essential part of the scientific process (Loehle 1990; Aslan et al. 2014). Extending creativity to how we communicate science can bring about unique deliverables (e.g., Dance Your Ph.D.; gonzolabs.org/dance) that have the potential to engage new audiences, including those with a limited interest in science (Dowell 2014; Sayer et al. 2014). For example, Guerilla Science is an organization that integrates creative science communication into leisure and entertainment events, including the Glastonbury music festival. In 2013, festival goers were able to navigate a human-sized rat maze, which was a replica of the radial arm maze test used in scientific research. The exhibit engaged participants in considering 
the contributions of animal models to scientific advancement, and related topics such as animal welfare. If you're interested in harnessing and honing your creativity try seeking out new sources of research information (e.g., poetry and historical records) and new venues for creative thinking (e.g., museums and nature reserves). Consider connecting with creative professionals and colleagues from communication, art, or journalism departments. When you feel comfortable with sharing your creative side, consider participating in events at familiar outlets of science communication (e.g., conferences) that use unfamiliar creative approaches (e.g., a poetry slam, which is a competition adjudicated on the recitation of original poetry). Poetry slams have occurred as social events at conferences (e.g., Bird Jam \& Poetry Slam at the 2016 North American Ornithological Conference) and as public events hosted by conference organizers (e.g., The Windy City Physics Slam at the 2016 International Conference on High Energy Physics). Integrating creativity and going beyond the lecture and the lecture hall when communicating science has thus far generated positive feedback from both audience and scientist participants (Bultitude and Sardo 2012; Dowell 2014; Sayer et al. 2014; Dance 2016).

\section{Focus on the science in science communication}

Good science is the foundation of quality science communication by scientists. Remember that people are interested in what you have to say because you have a unique science-based perspective on something they care about. High-profile results published in high-ranking journals should not be a prerequisite for science communication. Good science and a compelling story, however, are critical. Avoid patronizing an audience by oversimplifying or glossing over important scientific details, as interested people want to hear about the scientific process and see the data themselves. Discussing challenges, dead ends, and puzzles as well as results gives your work a narrative arc to which audiences can relate; be interesting, but also be yourself. Most importantly, be true to the data and don't oversell or overstate your results. If your data are interesting to you, they will be interesting to others.

\section{Be an honest broker}

Scientists are expected to avoid overextrapolating results beyond their own expertise and data (Pielke 2007). In a similar vein, be wary of sensationalizing and overpromising research outcomes. Focus on what you know. It's easy to speculate beyond one's expertise, but usually not advisable, as the audience (which may include policymakers and management authorities) is relying on you to offer the best interpretations that you can and that includes being open about what you don't know. If you choose to advocate a particular view or position, be clear as to when you are presenting your own opinions (Lackey 2007). Effective science communication is based heavily on trust, so be an honest broker.

\section{Understand the science of science communication}

Psychologists, sociologists, and communication scholars have a long history of studying how people engage with different types of science communication (Fischhoff 2013). Factors like perceived trustworthiness, reputation, values, political leanings, age, gender, educational background, and personal risk tolerance all have an effect on people's perceptions of a speaker and their message (Fiske and Dupree 2014). High-quality journals such as Public Understanding of Science (pus.sagepub.com/) and Science Communication (scx.sagepub.com/) offer a wealth of conceptual and empirical insight into the effectiveness of different techniques. Better communication can be learned. Peruse these sources to fuse the art and science of science communication or connect with researchers in these fields to learn more. 


\section{Think like an entrepreneur}

Borrow ideas from the startup world. Starting any new science communication platform, plan, or event is like starting and running a business, which requires marketing. The point of marketing is to build a brand and (or) reputation and to gain your audience's trust. As you develop your marketing approach, you will need to take risks (invest your time and reputation), convince people that you are worth the risk (find investors), secure support (financial, in-kind, and eventually both), and showcase yourself and your product (i.e., research).

\section{Don't let your colleagues stop you}

Free yourself from worrying about being seen as a self-promoter. Science communication is a public service and should be approached that way. If you are overly worried about what colleagues and peers think, you may limit yourself to appeasing only those people in your small professional bubble. However, you also want to ensure that whatever you are traditionally expected to do is getting done (e.g., an academic must also do teaching, service, and research) and done well, or you risk having your science communication activities viewed as problematic or unnecessary. Although the culture around science communication is changing, we all have a role to play in emphasizing its value during the hiring process or tenure and promotion assessments. Always ensure that your science communication is underpinned by high-quality science-your colleagues will definitely care about that.

\section{Integrate science communication into your research program}

Science communication is rarely top of mind during the research process, but it should be. People find the scientific process itself quite interesting (witness the interest in particle colliders, gene arrays, and animal tracking devices), not only the results and outcomes. Documenting the journey-for example, in still photos and video-can help tell the entire story of the research. You may not be able to comment on the findings, but there is much that can be shared about the journey. Doing so can also help stakeholders understand the realities of science: things like uncertainty, variation, trial and error, and the surprising and surreal moments we all experience when we learn something new.

\section{Recognize how science communication enhances your science}

Engaging in science communication does not have to detract from your science; in fact, it can enhance it. Although science communication does require time and resources that would otherwise be used toward science productivity, it doesn't have to be an either/or trade-off. Although it may take some more time and thought in the planning stages, you can figure out how to involve the public through citizen science, for example. Citizen scientists can play a role in everything from data collection (e.g., helping deploy traps, sort through photos, count trees) to data analysis (e.g., mapping craters, the debris ejected around them, and boulders/boulder fields, on the asteroid Vesta; see cosmoquest.org/x/science/vesta/). These citizen scientists may be a group of students or interns, or even people participating via online activities. Science communication can also bring attention to and increase the visibility of your work, which in turn can generate funding from non-traditional sources and help attract more talented students or staff that can directly increase scientific productivity. 


\section{Request science communication funds from grants}

Many funding agencies encourage and even require some form of science communication and engagement. As effective science communication can cost time and money, you can directly request funds for science communication in research grants. These funds can be used to support activities, buy tools, and even pay staff to do the communications for you (i.e., hiring a filmmaker). Moreover, if the science communication and research activities are synergistic (e.g., citizen science), funding for science communication will actually help fund the research itself. Additionally, science communication efforts may open up educational funding opportunities that, as a byproduct, help support the research.

\section{Strive for bidirectional communication}

Many of the tips covered here focus on one-way communication efforts. Although this is by far the most common modality adopted by scientists and engineers (see Davies 2008), one-way communication is not nearly as effective in influencing opinions and behaviours as communication activities that involve more direct public engagement with science. Efforts to engage in dialogue and participatory forms of engagement (including citizen science) are most likely to cause real and lasting behavioural change in participants (Monroe et al. 2008) and are captured in contemporary definitions of science communication (Burns et al. 2003; Bublea et al. 2009). Moreover, there is also opportunity for the science communicator (i.e., scientist) to learn from these interactions with the broader community, which can improve their research and subsequently reframe the way in which it is contextualized.

\section{Evaluate, reflect, and be prepared to adapt}

Science communication is an iterative process that requires continuous evaluation, reflection, and adaptation (Varner 2014). Depending on your goals (e.g., number of paper downloads versus changes in stakeholder attitude) and the communication medium itself, relatively straightforward tools can be used to evaluate success (e.g., built-in analytics of social media platforms). As science communication is also a multidirectional process among communicators and audiences, services can be sought from communication consultants to survey your audience and gauge the success of science communication efforts. ${ }^{1}$ Interpreting the data that these tools/services generate and determining the effectiveness of your efforts will also depend on the objectives of the science communication plan. It can be helpful to share your evaluation results with scientist colleagues and science communication practitioners. Keep in mind that the time of peak impact of your science communication will vary: a social media post is immediately digested by platform users, whereas impacts may be protracted for policy or management issues. When you choose to evaluate your efforts could influence the information gleaned. Evaluate your own knowledge base as well. Your communication skills will continue to broaden as you gain experience, ideas, and resources. Evaluate regularly, review and adjust goals as necessary, and anticipate and embrace the evolution of your science communication strategies.

\section{Conclusion}

The tips provided here are intended to guide scientists who are either planning to do-or are already engaged in-science communication. As the list is not exhaustive, we encourage those interested in science communication to read widely about science communication and access other helpful resources (see Box 1 for examples of common communication media and key references; see Table 1 for list of

\footnotetext{
${ }^{1}$ Note that there are ethical issues that arise from research that involves human participants and personal data. It is important to secure appropriate approvals.
} 
Box 1. Summary of common communication media.

There are many avenues available for science communication (see Kuehne et al. 2014 for a laundry list of approaches along with a thoughtful assessment of the relative time investment and benefits); in general, these techniques are not standalone and are in fact best when combined: for example, using various social media platforms to share a video abstract of your recent publication.

Video: A video abstract can summarize your work in a visually compelling way, illustrating your methods and outcomes in a way that a news piece or blog cannot portray (Berkowitz 2013). Videos can be a range of lengths from 60 s (Natural Sciences and Engineering Research Council of Canada's Science, Action!) to feature documentary length and involve any level of time or resources the researcher has available (creativity and teamwork go a long way). This approach has already garnered significant attention and support from the research community (e.g., in the form of science film festivals (Staaterman et al. 2014); see Fig. 1a, $1 b$; the ever-popular TED talk platform (Sugimoto and Thelwall 2013)), and some journals now require submission of a video abstract. As this technique tends not to suit in-depth or extensively technical content, it is best to link viewers to further resources to learn more. Key resources include: Donovan (2014); The Scientist Videographer (thescientistvideographer. com/wordpress).

Visual art/photography: Similar to video, visual art and photography appeal to the creative sense. These media can reach different audiences (e.g., via a gallery exhibition) and showcase the beauty of a scientific process that may not have been apparent previously (e.g., microscopy or macro-lens photography revealing images imperceptible to the human eye). Beyond the obvious photo-ops, there is also opportunity to generate comics or other graphic design features that resonate with the public (see Fig. 2). Key resources include: CommNatural (commnatural. com); Alex Wild (myrmecos.net).

Performance art/music: Theatre, dance, and music can all be effective means of scientific communication if ample care is taken to think carefully how to do so. If one does not have experience or expertise with these media, it may be possible to collaborate with creative professionals. Key resources include: Klionsky (2015).

Infographics: Visual representations of data can be an effective means for conveying simple or complex ideas. Good infographics involve the communication of facts and data by means of charts, graphs, maps, and diagrams in a visually stimulating way (Cairo 2013). Infographics are well-suited for print magazines and posters and can also be shared easily online in an electronic format (see Fig. 3). Key resources include: Mind the Graph (mindthegraph.com).

Social media: Social media platforms (Twitter, Facebook, Instagram, etc.) are excellent for sharing links to your work with a broad audience, or a target group (e.g., users of a Twitter hashtag (Darling et al. 2013), Facebook page), and also for conversing with colleagues and publics regarding your work, or a topic in general (e.g., Twitter or Reddit Q\&A with scientists; see Bik and Goldstein 2013; Parsons et al. 2013; Peoples et al. 2016). Social media, however, is very transient in that a post may appear only briefly upon a user's "feed" and requires both repetition and attentiveness to maximize effectiveness.

Speaking/public outreach: This technique spans day-to-day interactions and formal engagements. Engaging with colleagues, students, policymakers, and publics in an informal setting often requires condensing your science down to a quickly communicable and digestible vignette 
Box 1. (concluded)

(e.g., the elevator pitch), whereas conference presentations, public talks, or community outreach events allow for more in-depth explanations, while still ensuring the language is specifically geared to the audience at hand. Key resources include: Kwok (2013).

Press/popular media: If the opportunity arises (or is created by the researcher), this medium can be excellent for reaching a much broader audience (newspaper readers, frequenters of science news websites (e.g., ScienceDaily and Nature News)). However, the researcher themselves will likely be the subject, not the author, of the piece, so it is important to monitor the outcome for accuracy. Key resources include: Deep Sea News (deepseanews.com/2011/10/scientists-journalistsa-field-guide/); AAAS (aaas.org/page/tips-scientists-communicating-press); SIRC (sirc.org/ messenger/).

Blog: This mode allows the scientist (or even their graduate student team) to communicate their work in a more informal and personable way. Blogs provide an opportunity to share personal anecdotes of the process, digitally hyperlink to similar projects, and candidly explore future directions. Blogs may have wide readership or reach a very specific audience. Key resources include: Kouper (2010), Shema et al. (2012), Dennen (2014), and Jarreau (2016).

Curriculum: Working with educators and school boards to include topics related to your research in their curriculum can introduce new concepts to younger generations, with the opportunity for personal interaction with the researcher themselves (or their graduate student team). The time commitment may be higher than desired, so collaboration with education specialists is advantageous. Key resources include: University of Washington's Engage Program curriculum (courses.washington.edu/engageuw/seminar-resources/curriculum/).

web-based resources, many of which are lists of other resources). As a starting point, browse relevant blogs on science communication (e.g., From the Lab Bench, fromthelabbench.com; Science Communication Breakdown, sciencecommunicationbreakdown.wordpress.com; Science Borealis, scienceborealis.ca/) or follow the extensive discourse on science communication on Twitter via \#scicomm and \#sciengage. There is an increasing number of peer-reviewed papers that review communication and behavioural theories underpinning science communication, examine challenges of science communication, and provide practical advice on science communication (Brossard et al. 2005; Bik and Goldstein 2013). There are also papers that provide general guidance on science communication (e.g., Brossard and Scheufele 2013; Kuehne et al. 2014; Liang et al. 2014) as well as direction to those developing course materials to train others (including in the academy) in science communication (Trench 2012; Dilger and McKeith 2015; Hundey et al. 2016; LaRocca et al. 2016). There are also a growing number of organizations and companies that offer training or consultation services in science communication (e.g., compassonline.org; commnatural.com), or provide platforms for hosting science communication events (e.g., beneaththewaves.org). For those with specific interests in science communication related to the environment, we encourage you to consult general frameworks on environmental education and outreach (e.g., Monroe et al. 2008; Jacobson et al. 2015).

It is worth noting that science communication is being recognized as part of a broader set of skills and activities necessary to be relevant as a scientist (see Chapman et al. 2015; Peoples et al. 2016). We acknowledge we are neither professionally trained in science communication nor scholars of science 


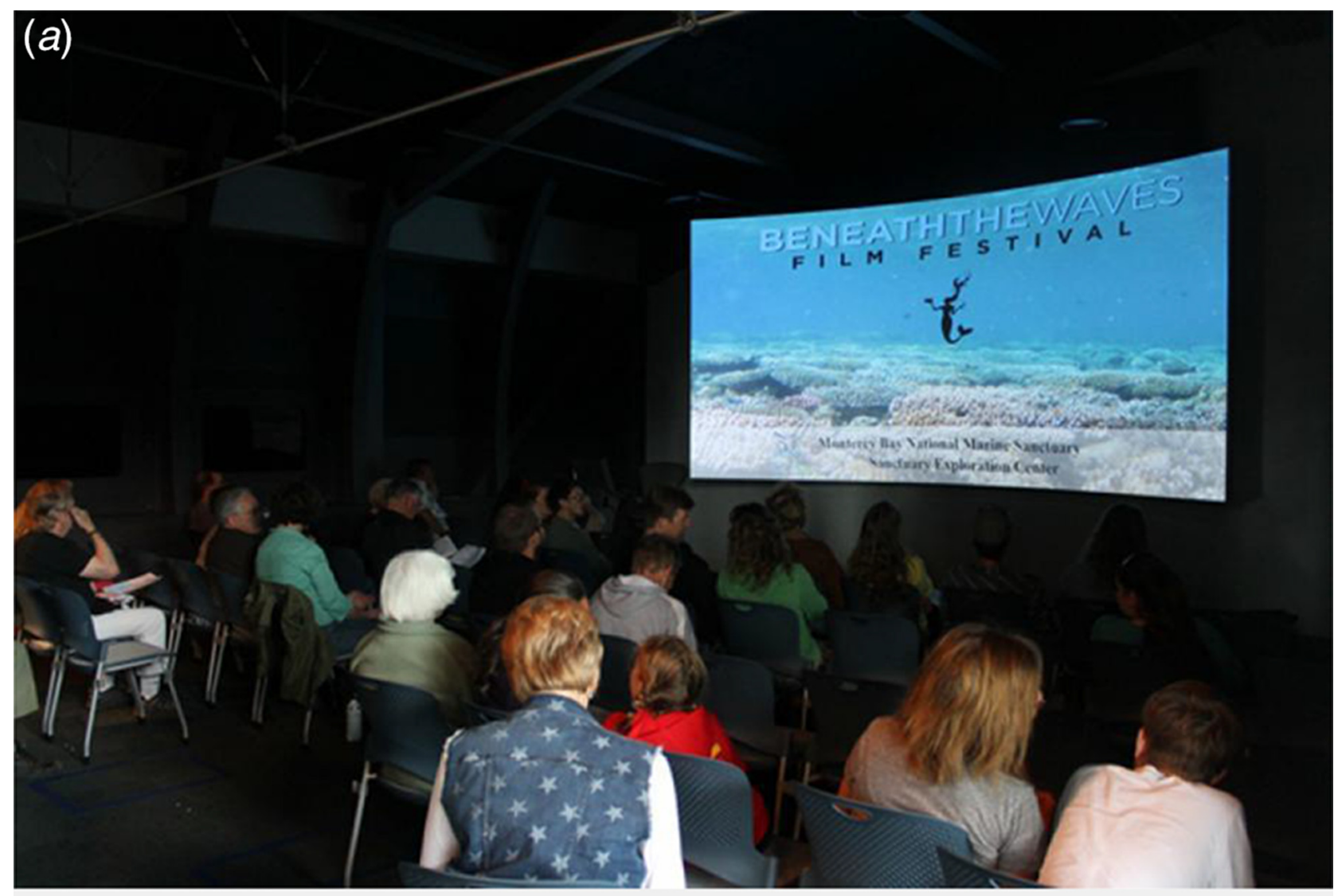

(b)

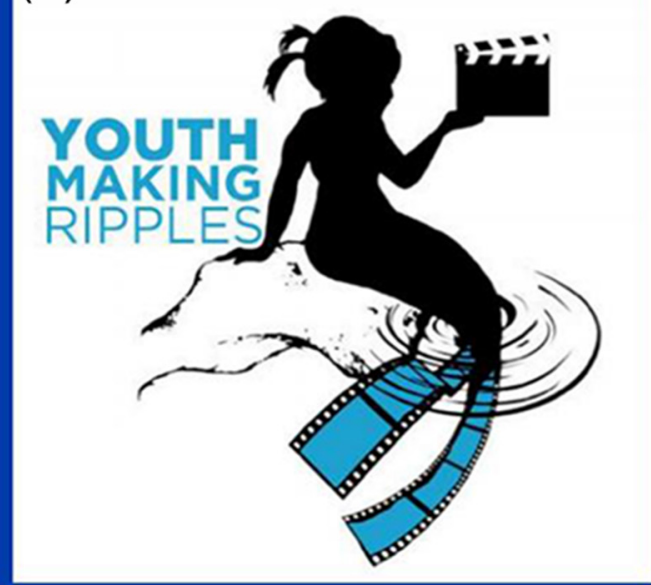

Youth Making Ripples is our film festival geared towards K-12 students. Students work individually or as teams to produce films about marine science or the threats facing our oceans. This film competition provides opportunities for young filmmakers to improve their storytelling abilities while serving as a voice for our oceans.

Fig. 1. (a) Image showing an audience participating in a Beneath The Waves (BTW; beneaththewaves.org) film festival. BTW film festivals occur in different locations around the globe and feature a handful of films from their collection highlighting local and global conservation issues. At the end of the films, the audience interacts with invited scientists and engages in informal discussion about science and aquatic conservation. There is also a series of events $(b)$ targeted toward youth and delivered in schools. Images courtesy of Beneath The Waves and used with permission. 


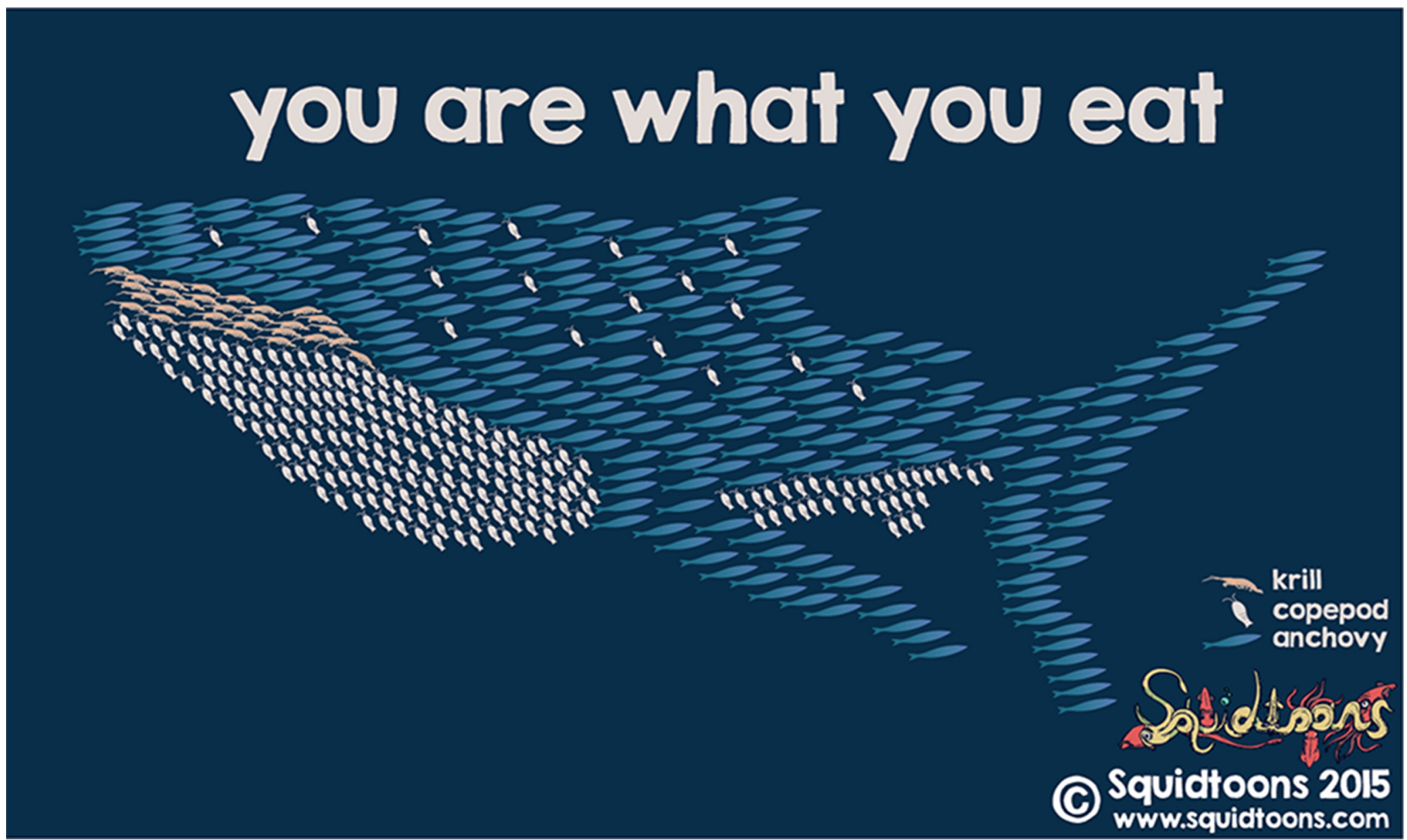

Fig. 2. Cartoon demonstrating the simple concept of trophic ecology. Image courtesy of Squidtoons (squidtoons.com/) and used with permission. 


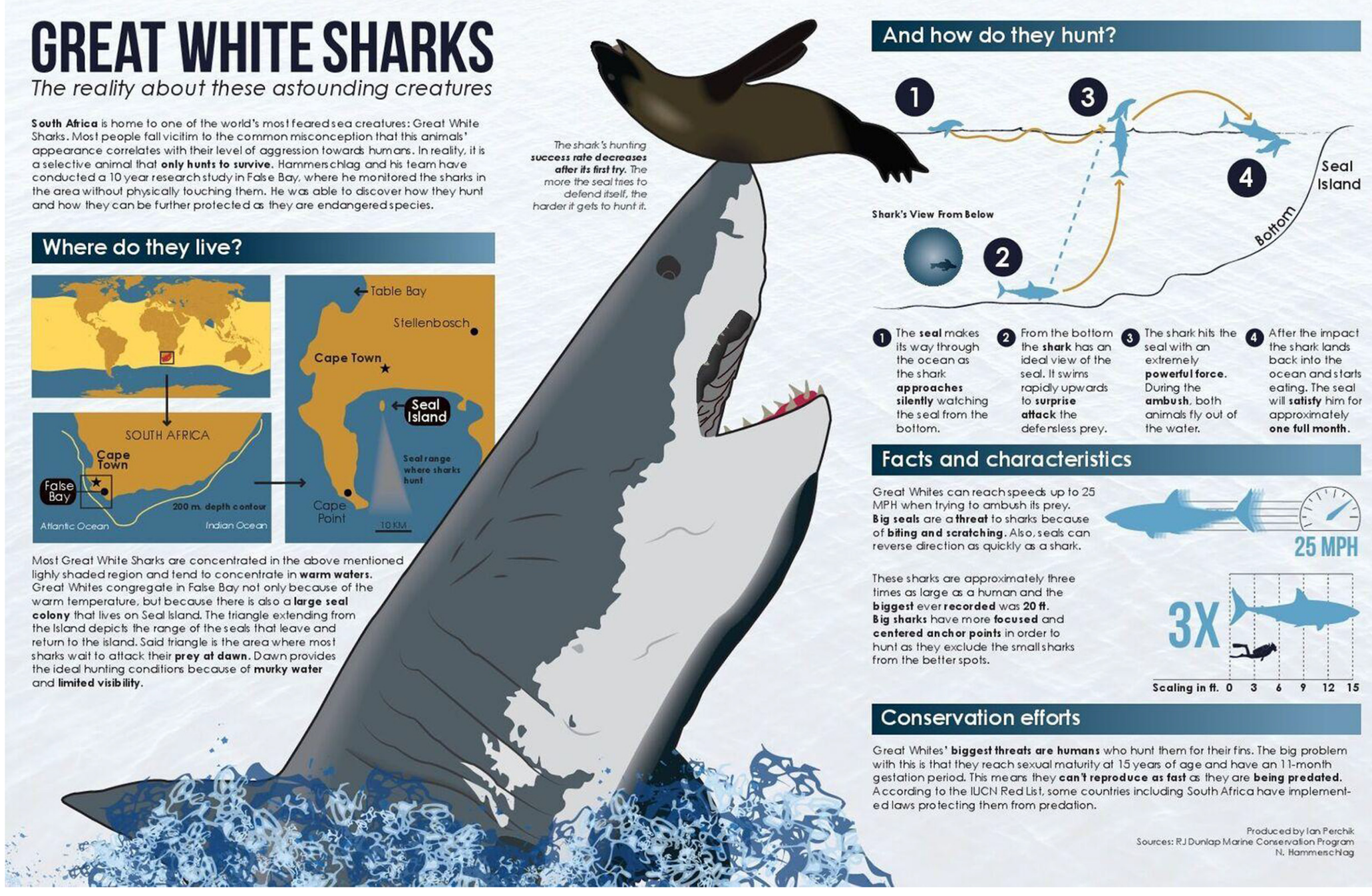

Fig. 3. Infographic on the ecology of great white sharks. Image courtesy of Neil Hammerschlag, University of Miami. 
communication. Indeed, most of what we have learned about science communication has not come from a classroom or a journal article, but rather by simply giving it a try. Importantly, we have learned much about science communication by discussing it with like-minded individuals and by making mistakes along the way. Those engaged and proficient in science communication are often very forthcoming with ideas and willing to mentor those new to science communication. We hope that the ideas shared here will resonate with readers and in doing so will encourage them to engage in science communication. For those already active in science communication, we hope that these ideas will increase the effectiveness of their communication activities and that they will be empowered to mentor others wishing to become more involved with science communication.

\section{Acknowledgements}

Cooke is supported by NSERC and the Canada Research Chairs Program. Cooke, Young, and Nguyen are further supported by Ocean Tracking Network Canada. Sopinka is supported by Mitacs. Gallagher is supported by Beneath the Waves.

\section{Author contributions}

Conceived and designed the study: SJC, AJG, RAS, NH. Drafted or revised the manuscript: SJC, AJG, NMS, VMN, RAS, NH, SB, NY, AJD.

\section{Competing interests}

AJG is the CEO of Beneath The Waves, which engages in science communication. SB is a writer for Science Borealis. NMS was a freelance contributor to the Canadian Science Publishing blog, now employed by Canadian Science Publishing, but was not involved in review or editorial decisions regarding this manuscript. SJC is currently serving as a Subject Editor for FACETS, but was not involved in review or editorial decisions regarding this manuscript.

\section{Data accessibility statement}

All relevant data are within the paper.

\section{References}

Aslan CE, Pinsky ML, Ryan ME, Souther S, and Terrell KA. 2014. Cultivating creativity in conservation science. Conservation Biology, 28(2): 345-353. PMID:24283793. doi:10.1111/cobi.12173.

Berkowitz J. 2013. Video abstracts, the latest trend in scientific publishing. University Affairs, Feb. 6. http://www.universityaffairs.ca/features/feature-article/video-abstracts-the-latest-trend-in-scientificpublishing/.

Bik HM, and Goldstein MC. 2013. An introduction to social media for scientists. PLoS Biology, 11(4): e1001535. doi:10.1371/journal.pbio.1001535.

Brossard D, Lewenstein B, and Bonney R. 2005. Scientific knowledge and attitude change: the impact of a citizen science project. International Journal of Science Education, 27(9): 1099-1121. doi:10.1080/ 09500690500069483.

Brossard D, and Scheufele DA. 2013. Science, new media, and the public. Science, 339(6115): 40-41. PMID:23288529. doi:10.1126/science.1232329.

Bublea T, Nisbet MC, Borchelt R, Brungers F, Critchley C, Einsiedel E, et al. 2009. Science communication reconsidered. Nature Biotechnology, 27: 514-518. doi:10.1038/nbt0609-514. 
Bultitude K, and Sardo AM. 2012. Leisure and pleasure: science events in unusual locations. International Journal of Science Education, 34(18): 2775-2795. doi:10.1080/09500693.2012.664293.

Burns TW, O'Connor DJ, and Stocklmayer SM. 2003. Science communication: a contemporary definition. Public Understanding of Science, 12(2): 183-202. doi:10.1177/09636625030122004.

Cairo A. 2013. The functional art: an introduction to information graphics and visualization. New Riders, Berkeley, California. 363 p.

Chapman JM, Algera D, Dick M, Hawkins EE, Lawrence MJ, Lennox RJ, et al. 2015. Being relevant: practical guidance for early career researchers interested in solving conservation problems. Global Ecology and Conservation, 4: 334-348. doi:10.1016/j.gecco.2015.07.013.

Dance A. 2016. Science and culture: avant-garde outreach, with science rigor. Proceedings of the National Academy of Sciences, 113(43): 11982-11983. doi:10.1073/pnas.1615469113.

Darling ES, Shiffman D, Côté IM, and Drew JA. 2013. The role of Twitter in the life cycle of a scientific publication. Ideas in Ecology and Evolution, 6(1): 32-43. doi:10.4033/iee. 2013.6.6.f.

Davies SR. 2008. Constructing communication: talking to scientists about talking to the public. Science Communication, 29: 413-434. doi:10.1177/1075547008316222.

Dennen VP. 2014. Becoming a blogger: trajectories, norms, and activities in a community of practice. Computers in Human Behavior, 36: 350-358. doi:10.1016/j.chb.2014.03.028.

Dilger AC, and McKeith FK. 2015. Training graduate students to communicate science to broad audiences. Animal Frontiers, 5(3): 60-63.

Donovan J. 2014. How to deliver a TED talk. McGraw Hill, New York, New York.

Dowell E. 2014. Einstein's Garden 2009-2014: unexpected encounters with science. Journal of Science Communication, 13(4): C06.

Durant JR, Evans GA, and Thomas GP. 1989. The public understanding of science. Nature, 340(6228): 11-14. PMID:2739718. doi:10.1038/340011a0.

Fischhoff B. 2013. The sciences of science communication. Proceedings of the National Academy of Sciences, 110(3): 14033-14039. doi:10.1073/pnas.1213273110.

Fiske ST, and Dupree C. 2014. Gaining trust as well as respect in communicating to motivated audiences about science topics. Proceedings of the National Academy of Sciences, 111(4): 13593-13597. doi:10.1073/pnas.1317505111.

Glanz K, and Bishop DB. 2010. The role of behavioral science theory in development and implementation of public health interventions. Annual Review of Public Health, 31: 399-418. PMID:20070207. doi:10.1146/annurev.publhealth.012809.103604.

Hundey EJ, Olker JH, Carreira C, Daigle RM, Elgin AK, Finiguerra M, et al. 2016. A shifting tide: recommendations for incorporating science communication into graduate training. Limnology and Oceanography Bulletin, 25(4): 109-116. doi:10.1002/lob.10151.

Jacobson SK, McDuff MD, and Monroe MC. 2015. Conservation education and outreach techniques. 2nd edition. Oxford University Press, Oxford, UK. 428 p. 
Jarreau P. 2016. New roles for science blogs in shifting sci-pub landscape. PLoS Blogs SciComm. June 21 [online]: Available from http://blogs.plos.org/scicomm/2016/06/ 21/new-roles-for-science-blogs-in-shifting-sci-pub-landscape-paige-jarreau-scrubs-data-from-2016plosblogs-reader-survey/.

Klionsky DJ. 2015. Autophagy: research topic, painting, poem, dance... : the combination of art and information can enhance the enjoyment and effectiveness of learning. EMBO Reports, 16(5): 547-552. PMID:25838538. doi:10.15252/embr.201540400.

Kouper I. 2010. Science blogs and public engagement with science: practices, challenges, and opportunities. Journal of Science Communication, 9(1): 1-10.

Kuehne LM, Twardochleb LA, Fritschie KJ, Mims MC, Lawrence DJ, Gibson PP, et al. 2014. Practical science communication strategies for graduate students. Conservation Biology, 28(5): 1225-1235. PMID:24762116. doi:10.1111/cobi.12305.

Kwok R. 2013. Communication: two minutes to impress. Nature, 494(7435): 137-138. PMID:23393652. doi:10.1038/nj7435-137a.

Lackey RT. 2007. Science, scientists, and policy advocacy. Conservation Biology, 21(1): 12-17. PMID:17298504. doi:10.1111/j.1523-1739.2006.00639.x.

LaRocca TJ, Justice JN, Seals DR, and Martens CR. 2016. Adding value to a graduate physiology seminar by focusing on public communication skills. Advances in Physiology Education, 40: 365-369. PMID:27445287. doi:10.1152/advan.00183.2015.

Liang X, Su LY-F, Yeo SK, Scheufele DA, Brossard D, Xenos M, et al. 2014. Building buzz: (scientists) communicating science in new media environments. Journalism \& Mass Communication Quarterly, 91(4): 772-791. doi:10.1177/1077699014550092.

Loehle C. 1990. A guide to increased creativity in research-inspiration or perspiration? Bioscience, 40(2): 123-129. doi:10.2307/1311345.

Logan RA. 2001. Science mass communication: its conceptual history. Science Communication, 23(2): 135-163. doi: $10.1177 / 1075547001023002004$.

Meyer M. 2010. The rise of the knowledge broker. Science Communication, 32(1): 118-127. doi:10.1177/1075547009359797.

Monroe MC, Andrews E, and Biedenweg K. 2008. A framework for environmental education strategies. Applied Environmental Education \& Communication, 6(3-4): 205-216. doi:10.1080/ 15330150801944416.

Nisbet MC, and Scheufele DA. 2009. What's next for science communication? Promising directions and lingering distractions. American Journal of Botany, 96(10): 1767-1778. PMID:21622297. doi:10.3732/ajb.0900041.

Parsons ECM, Shiffman DS, Darling ES, Spillman N, and Wright AJ. 2013. How twitter literacy can benefit conservation scientists. Conservation Biology, 28(2): 299-301. PMID:24372742. doi:10.1111/ cobi.12226.

Peoples BK, Midway SR, Sackett D, Lynch A, and Cooney PB. 2016. Twitter predicts citation rates of ecological research. PLoS ONE, 11(11): e0166570. doi:10.1371/journal.pone.0166570. 
Pielke RA Jr. 2007. The honest broker: making sense of science in policy and politics. Cambridge University Press, New York, New York, USA. 188 p.

Poliakoff E, and Webb TL. 2007. What factors predict scientists' intentions to participate in public engagement of science activities? Science Communication, 29(2): 242-263. doi:10.1177/ 1075547007308009.

Sayer EJ, Featherstone HC, and Gosling WD. 2014. Sex \& Bugs \& Rock 'n Roll-getting creative about public engagement. Trends in Ecology \& Evolution, 29(2): 65-67. PMID:24388288. doi:10.1016/j. tree.2013.12.008.

Shema H, Bar-Ilan J, and Thelwall M. 2012. Research blogs and the discussion of scholarly information. PloS ONE, 7(5): e35869. PMID:22606239. doi:10.1371/journal.pone.0035869.

Staaterman ER, Bhandiwad AA, Gravinese PM, Moeller PM, Reichenbach ZC, Shantz AA, et al. 2014. Lights, camera, science: the utility and growing popularity of film festivals at scientific meetings. Ideas in Ecology and Evolution, 7(1): 11-16. doi:10.4033/iee.2014.7.4.f.

Sugimoto CR, and Thelwall M. 2013. Scholars on soap boxes: science communication and dissemination in TED videos. Journal of the American Society for Information Science and Technology, 64: 663-674. doi:10.1002/asi.22764.

Sugimoto CR, Thelwall M, Larivière V, Tsou A, Mongeon P, and Macaluso B. 2013. Scientists popularizing science: characteristics and impact of TED talk presenters. PLoS ONE, 8(4): e62403. PMID:23638069. doi:10.1371/journal.pone.0062403.

Treise D, and Weigold MF. 2002. Advancing science communication: a survey of science communicators. Science Communication, 23(3): 310-322. doi:10.1177/107554700202300306.

Trench B. 2012. Vital and vulnerable: science communication as a university subject. In Science communication in the world. Edited by B Schiele, M Claessens, and S Shi. Springer, Dordrecht, Netherlands. pp. 241-257.

Varner J. 2014. Scientific outreach: toward effective public engagement with biological science. BioScience, 64(4): 333-340. doi:10.1093/biosci/biu021.

Weigold MF. 2001. Communicating science: a review of the literature. Science Communication, 23(2): 164-193. doi:10.1177/1075547001023002005.

Wilson MJ, Ramey TL, Donaldson MR, Germain RR, and Perkin EK. 2016. Communicating science: Sending the right message to the right audience. FACETS, 1: 127-137. doi:10.1139/facets-2016-0015.

Yeo SK, Liang X, Brossard D, Rose KM, Korzekwa K, Scheufele DA, et al. In press. The case of \#arseniclife: Blogs and Twitter in informal peer review. Public Understanding of Science. doi:10.1177/ 0963662516649806. 